\title{
Effect of various levels of selenium in wheat and meat on blood Se status indices and on Se balance in Dutch men
}

\author{
BY HETTY W. VAN DER TORRE, WIM VAN DOKKUM*, \\ GERTJAN SCHAAFSMA, MICHEL WEDEL AND THEO OCKHUIZEN \\ Division of Nutrition and Food Research TNO, CIVO Institutes, PO Box 360, 3700 AJ Zeist, \\ The Netherlands
}

(Received 11 October 1989 - Accepted 15 June 1990)

\begin{abstract}
After a 5-week period of low selenium intake, twenty-four Dutch men received 55, 135 or $215 \mu \mathrm{g} \mathrm{Se/d}$ as Se-rich meat or bread for a 9-week period. Four unsupplemented subjects served as controls. Plasma Se increased more rapidly than erythrocyte Se levels; the increases were significantly dependent $(P<$ $0.001)$ on Se intake level. Glutathione peroxidase (EC 1.11.1.9; GSH-Px) activity in platelets increased rapidly after supplementation and plateaued after 4-9 weeks. At 10 weeks after supplementation ended, plasma Se levels and platelet GSH-Px were still higher than the baseline values whereas erythrocyte Se levels continued to increase. Except for the higher erythrocyte Se levels after supplementation with high-Se meat, there were no differences in bioavailability of Se between meat and wheat products. Daily urinary and faecal Se excretions as well as Se retention increased with an increased Se intake irrespective of the form of the supplement. Regression of Se excretion v. intake indicated that $33 \mu \mathrm{g} \mathrm{Se} / \mathrm{d}$ is necessary to compensate for urinary and faecal losses.
\end{abstract}

Selenium bioavailability: Selenium balance: Meat: Wheat: Dutch men

The intake of dietary selenium ranges from less than $10 \mu \mathrm{g} / \mathrm{d}$ in Se-deficient areas (Luo et al. $1985 \mathrm{~b}$ ) to about $5000 \mu \mathrm{g} / \mathrm{d}$ in areas where selenosis is endemic (Yang et al. 1983). Although Se toxicity led to initial investigations of Se, most research interest in the past decade has concentrated on the essential role of Se.

Beneficial effects of Se supplementation have been observed in people living in low-Se areas in China (Keshan Disease Research Group, 1979 $a, b$ ) as well as among people receiving parenteral nutrition (Van Rij et al. 1979). Moreover, interest in Se intake and supplementation has been increased by reports indicating that an adequate or high $\mathrm{Se}$ status may protect against cancer (Ip, 1985, 1988).

There is no consensus as to optimal Se intake. Moreover, the bioavailability of Se may differ among different food sources. Bioavailability not only depends on absorption of the element, but also on its conversion into a biologically active form. This can be influenced by many factors, such as the chemical form of the element or interactions with dietary components.

So far, there have been few studies on Se bioavailability in man (Levander et al. 1983; Luo et al. 1985a; Thomson et al. 1985; Mutanen, 1986). These studies were based on the response of Se level and activity of the Se-containing enzyme glutathione peroxidase (EC 1.11.1.9; GSH-Px) in different blood compartments to daily supplementation with organic or inorganic Se compounds. From these studies it is known that the organic forms of Se, especially selenomethionine, are more capable of increasing blood Se levels than are 
the inorganic selenates and selenites. However, organic and inorganic forms were equally effective in raising blood GSH-Px activity (Thomson et al. 1982).

Studies on food Se sources have shown that the bioavailability of Se is high from wheat and low from mushrooms (Levander et al. 1983; Mutanen, 1986).

Most studies emphasize Se bioavailability in individual foods or discrete Se compounds. However, because of the many possible interactions it is important to study the effects of Se within the total diet.

Therefore, the present study was designed to examine the effects of various levels of Se intake from natural sources as a component of the complete daily diet, composed of habitual foodstuffs, on various Se status indices and Se balance.

To estimate Se status, the indices used should reflect Se intake over a range that is applicable to the target group in question. So, three different Se intake levels were chosen to evaluate Se status indices, i.e. 55,135 and $215 \mu \mathrm{g} \mathrm{Se} / \mathrm{d}$, corresponding with the lower, medium and upper values of the recommended safe and adequate dietary intake of 50-200 $\mu \mathrm{g} / \mathrm{d}$ respectively (Food and Nutrition Board, 1980).

Bread and meat products were chosen for Se supplementation since these are the main sources of Se in the Dutch diet. The different Se intake levels were achieved by utilizing the natural variation of the Se content in these products, without changing the total amounts of product consumed.

\section{METHODS}

\section{Subjects}

Twenty-eight healthy male subjects, aged 20-30 years, participated in the study. They were recruited from a student population. The selection criteria included an erythrocyte Se concentration lower than $115 \mathrm{ng} / \mathrm{g}$, a habitual Dutch dietary pattern as evaluated by questionnaire, no vitamin supplement use and no smoking. A routine haematological test and clinical examination formed part of the selection procedure. Plasma tocopherol levels were in the range of $7-15 \mathrm{mg} / 1$, plasma total cholesterol concentration was below 5.7 mmol/l. All subjects gave written informed consent. One subject left the experiment prematurely for personal reasons. The study protocol was approved by the Institute's external Medical Ethical Committee.

\section{Experimental design}

A factorial design was used with Se intake and Se source as factors. The intervention trial consisted of a 5-week period of low Se intake (27-43 $\mu \mathrm{g} \mathrm{Se} / \mathrm{d} ; n 23)$, followed by a 9-week period during which the Se intake was either 55 (group 1, $n 8$ ), 135 (group 2, $n 7$ ) or 215 (group 3, $n 8) \mu \mathrm{g} / \mathrm{d}$. The subjects were randomized over the three groups. In each group, half the subjects were randomly assigned to Se supplementation through naturally Se-rich bread (b), and the other half through naturally Se-rich meat (m). The Se intakes over both periods are summarized in Table 1 . The amounts of Se differed unintentionally between the meat and bread supplements within each supplementation group with the same intake level. Except for Se content the basal diet was constant during both periods mentioned. Finally all subjects were on a self-selected diet for 10 weeks (post-intervention period).

A control group of four subjects (group C) was supplied with low-Se bread. Their dietary Se intake was restricted throughout the experiment by giving them instructions regarding Se-rich food. Their estimated mean daily dietary Se intake amounted to about $50 \mu \mathrm{g} / \mathrm{d}$ (Van Dokkum et al. 1989).

The study was performed in the Institute's metabolic ward. For practical reasons, the experiment was conducted in two periods, February 1987 (group 1), and August 1987 (groups 2, 3 and C). For logistic reasons, group C started 2 weeks after groups 2 and 3. 
Table 1. Selenium intake in the low-Se period (weeks 0-5) and in the period of Se supplementation (weeks 5-14) and the Se sources during weeks 5-14

\begin{tabular}{ccccc}
\hline & & \multicolumn{2}{c}{ Se intake $(\mu \mathrm{g} / \mathrm{d})$} & \\
Dietary group & $n$ & weeks 0-5 & weeks 5-14 & $\begin{array}{l}\text { Source of Se } \\
\text { weeks 5-14 }\end{array}$ \\
\hline $1 \mathrm{~b}$ & 4 & 27 & 68 & Bread \\
$1 \mathrm{~m}$ & 4 & 27 & 42 & Meat \\
$2 \mathrm{~b}$ & 4 & 43 & 140 & Bread \\
$2 \mathrm{~m}$ & 3 & 43 & 129 & Meat \\
$3 \mathrm{~b}$ & 4 & 43 & 227 & Bread \\
$3 \mathrm{~m}$ & 4 & 43 & 205 & Meat \\
\hline
\end{tabular}

b, Bread; m, meat.

Dinners were served at the Institute. The two cold meals, snacks, coffee, tea and beverages were provided and could be consumed elsewhere. The food was prepared according to standard procedures, weighed to the nearest gram, packed in individual portions and deep frozen when necessary. The bread Se source was given daily as six rolls, the meat Se source as daily portions of $150 \mathrm{~g}$ minced meat. There was no restriction as to the use of tap water.

Reduction of body-weight of more than $5 \%$ during the study was corrected by supplying a snack without Se. This was done for eight subjects.

Fasting blood samples for Se and GSH-Px analysis were taken between 08.00 and 09.00 hours at the beginning of the experiment (week 0) and after 3, 5 (start of the supplementation period), 6, 9 and 14 weeks (end of supplementation). Finally, a blood sample was taken at the end of the 10 -week post-intervention period.

Urine and all stools $(24 \mathrm{~h})$ were collected for the last $8 \mathrm{~d}$ before the intervention trial started, for the last $12 \mathrm{~d}$ of the 5-week period of low Se intake, and for the last $12 \mathrm{~d}$ of the 9 -week period of Se supplementation. No balance information was obtained from the four controls.

\section{Analytical methods}

Blood samples were collected free-flowing in polycarbonate tubes containing sodiumethylenediaminetetra-acetic acid (Na-EDTA) as anticoagulant and separated by centrifugation into platelet-rich plasma (PRP), platelet-poor plasma (PPP) and erythrocytes. PRP was obtained after centrifugation at $200 \mathrm{~g}$ at room temperature for $10 \mathrm{~min}$. PPP was separated from erythrocytes after centrifugation at $1700 \mathrm{~g}$ for another $10 \mathrm{~min}$. The PRP was centrifuged $\left(1700 \mathrm{~g}, 10 \mathrm{~min}, 4^{\circ}\right)$ and washed by resuspending the platelet pellet in a cold wash buffer ( $\mathrm{pH} \mathrm{6.5)}$. The composition of the buffer was: six parts of buffer A (137 mMsodium chloride, 2.7 mm-potassium chloride, $8.1 \mathrm{~mm}$-disodium hydrogen phosphate, $1.5 \mathrm{~mm}$ potassium hydrogen phosphate) and one part of buffer B (85 mm-sodium citrate, $71 \mathrm{~mm}$-citric acid, $111 \mathrm{~mm}$-D-glucose). The platelets were finally resuspended in 0.32 $\mathrm{M}$-sucrose. The erythrocytes were washed with saline $(9 \mathrm{~g} \mathrm{NaCl} / 1)$. Urine and faeces were measured or weighed in the morning after each $24 \mathrm{~h}$ period. Urine samples $(24 \mathrm{~h})$ were collected in polyethylene bottles with $10 \mathrm{ml} 5 \mathrm{~m}$-hydrochloric acid as preservative. Faecal samples were collected in plastic buckets, one for every defaecation. Samples of urine and faeces $(4 \mathrm{~d})$ were pooled for analysis of Se. All samples for analysis of Se and GSH-Px were stored at -20 and $-80^{\circ}$ respectively. 
Se was measured by a fluorimetric method (Koh \& Benson, 1983). The GSH-Px activity was assayed according to Pleban et al. (1982), using a Cobas Bio centrifugal analyser. Protein was determined by the method of Lowry et al. (1951). Plasma tocopherol levels were determined by high-pressure liquid chromatography (Tangney et al. 1981). Plasma total cholesterol was measured by an enzymic colorimetric autoanalyser method (Testcombination Cholesterol, CHOD-PAP Enzymatic Colorimetric Method, Boehringer Mannheim, FRG).

\section{Statistical methods}

Statistical analysis comprised analysis of variance (ANOVA) according to the design used (factorial design with added control) (Cochran \& Cox, 1957; Snedecor \& Cochran, 1967). In order to investigate between which points of time the supplemented group increased significantly compared with the control group, the differences between measurements at weeks 3 and 0,5 and 3,6 and 5,9 and 6, 14 and 9 respectively, weeks 24 and 14 were analysed by ANOVA to test the main effects and the first-order interaction of Se level (groups 1, 2, 3) and Se source (bread, meat).

\section{RESULTS}

Se status indices. Since the effects of supplementation on the indices measured in the present study appeared independent of the Se source (the interactions between supplementation and source as well as the source main effects being non-significant), the data of both subgroups (meat and wheat) were combined for each Se intake level. The only exception was the change in erythrocyte Se levels between weeks 14 and 24, which will be described below.

Baseline Se indices were similar in all groups and showed no significant change during the period of low Se intake in the treatment groups (data not shown). Once the Se supplementation had started, significant differences in changes in plasma Se levels were observed between the treatment groups and the control group and between the three treatment groups (Table 2 and Fig. 1). During the first 4 weeks of supplementation, the changes in plasma Se (from weeks 5-6, and 6-9) were significantly dependent on Se intake level $(P<0.001)$, after which the increases appeared to slow down. Se levels in groups 2 and 3 continued to increase from week 9 to week 14 , but stabilized in groups 1 and $C$. At the end of the post-intervention period the changes in plasma Se levels compared with week 14 differed significantly between all groups, the greatest decline being found in groups 2 and 3. However, plasma Se levels were still above baseline levels in these two groups. Plasma $\mathrm{Se}$ in the control group did not change during the experimental period.

Erythrocyte Se levels did not change significantly during the first week of supplementation, whereafter a gradual increase was observed in the two groups with the highest Se intake levels (groups 2 and 3) with no sign of plateauing (Table 2 and Fig. 2). Moreover, after the supplementation had been discontinued the erythrocyte Se levels increased a little further; this increase was significantly higher $(P=0.011)$ in the subjects receiving the meat supplements, independent of Se intake levels. Erythrocyte Se levels remained constant in the group with the lowest supplementation level (group 1) and showed a slight decrease in the control group.

The activity of GSH-Px in plasma and erythrocytes hardly showed significant changes during the intervention trial (Table 2). The plasma enzyme activity decreased slightly at the end of the period of low Se intake, but recovered rapidly during the first week of supplementation. 
Table 2. Effect of low-selenium intake and Se supplementation on Se levels and glutathione peroxidase (EC 1.11.1.9; GSH-Px) activity

(Mean values and standard deviations)

\begin{tabular}{|c|c|c|c|c|c|c|c|c|c|c|c|}
\hline & & \multicolumn{8}{|c|}{ Se supplementation* } & \multicolumn{2}{|c|}{ Post-intervention } \\
\hline \multicolumn{2}{|c|}{ Week of study ... } & 5 & & \multicolumn{2}{|c|}{6} & \multicolumn{2}{|c|}{9} & \multicolumn{2}{|c|}{14} & \multicolumn{2}{|c|}{24} \\
\hline group $\dagger$ & $n$ & Mean & $\mathrm{SD}$ & Mean & SD & Mean & $\mathrm{SD}$ & Mean & SD & Mean & SD \\
\hline \multicolumn{12}{|c|}{ Se in plasma $(n g / g)$} \\
\hline 1 & 8 & 69 & 6 & $74^{\mathrm{a}}$ & 8 & $82^{\mathrm{a}}$ & 12 & $85^{\text {ab }}$ & 8 & $80^{\mathrm{a}}$ & 7 \\
\hline 2 & 7 & 72 & 7 & $93^{\mathrm{b}}$ & 8 & $111^{\mathrm{b}}$ & 11 & $122^{\mathrm{a}}$ & 13 & $101^{\mathrm{b}}$ & 10 \\
\hline 3 & 8 & 65 & 5 & $98^{\circ}$ & 11 & $125^{\mathrm{c}}$ & 14 & $138^{a}$ & 13 & $98^{\circ}$ & 10 \\
\hline $\mathrm{C}$ & 4 & 73 & 5 & $74^{\mathrm{a}}$ & 7 & $76^{\mathrm{a}}$ & 9 & $74^{\mathrm{b}}$ & 3 & $80^{d}$ & 4 \\
\hline \multicolumn{12}{|c|}{ Se in erythrocytes $(\mathrm{ng} / \mathrm{g})$} \\
\hline 1 & 8 & 84 & 10 & 83 & 8 & $84^{\mathrm{a}}$ & 7 & $86^{\mathrm{a}}$ & 9 & 91 & 13 \\
\hline 2 & 7 & 84 & 13 & 86 & 13 & $95^{\mathrm{b}}$ & 16 & $109^{\mathrm{b}}$ & 18 & 118 & 26 \\
\hline 3 & 8 & 90 & 15 & 88 & 14 & $106^{\mathrm{b}}$ & 15 & $143^{\circ}$ & 22 & 155 & 22 \\
\hline C & 4 & 94 & 6 & 96 & 11 & $90^{\mathrm{e}}$ & 12 & $86^{\mathrm{a}}$ & 9 & 87 & 4 \\
\hline \multicolumn{12}{|c|}{$G S H-P_{x}$ in plasma $(U / g$ protein $)$} \\
\hline 1 & 8 & $4 \cdot 1$ & $0 \cdot 5$ & $3 \cdot 9^{\mathrm{a}}$ & 0.5 & 4.0 & $0 \cdot 5$ & $4 \cdot 1$ & 0.6 & $4 \cdot 1$ & $0-3$ \\
\hline 2 & 7 & $4 \cdot 3$ & $0 \cdot 7$ & $4 \cdot 6^{\mathrm{ah}}$ & 0.7 & $4 \cdot 8$ & $0 \cdot 8$ & $5 \cdot 1$ & 0.9 & $5 \cdot 4$ & $0 \cdot 6$ \\
\hline 3 & 8 & $4 \cdot 3$ & $0 \cdot 6$ & $4 \cdot 8^{b}$ & 0.7 & 4.9 & $0 \cdot 7$ & $4 \cdot 9$ & 0.5 & $4 \cdot 8$ & 0.5 \\
\hline $\mathrm{C}$ & 4 & $4 \cdot 8$ & $0 \cdot 4$ & $4 \cdot 8^{\mathrm{al}}$ & 0.6 & $4 \cdot 9$ & $0 \cdot 8$ & $4 \cdot 9$ & 0.6 & $4 \cdot 6$ & $0 \cdot 5$ \\
\hline \multicolumn{12}{|c|}{$G S H-P x$ in erythrocytes $(U / g H b)$} \\
\hline 1 & 8 & $4 \cdot 6$ & $0 \cdot 4$ & $4 \cdot 6$ & 0.4 & $4 \cdot 4$ & $0 \cdot 4$ & $4 \cdot 8$ & $0 \cdot 5$ & $4 \cdot 6$ & 06 \\
\hline 2 & 7 & $5 \cdot 4$ & 0.6 & $5 \cdot 4$ & 0.5 & $5 \cdot 5$ & 0.7 & $5 \cdot 7$ & 0.7 & 5.8 & 1.0 \\
\hline 3 & 8 & $5 \cdot 5$ & $0 \cdot 9$ & $5 \cdot 6$ & 0.9 & $5 \cdot 7$ & $1 \cdot 1$ & 6.2 & $1 \cdot 9$ & 5.9 & 1.8 \\
\hline C & 4 & $5 \cdot 2$ & 0.4 & $5 \cdot 0$ & 1.7 & $5 \cdot 3$ & 0.4 & $5 \cdot 3$ & $0 \cdot 3$ & $4 \cdot 7$ & 0.3 \\
\hline \multicolumn{12}{|c|}{ GSH-PX in platelets (U/g protein) } \\
\hline $\begin{array}{l}1 \\
2\end{array}$ & 7 & 209 & 12 & 226 & 13 & $299^{\mathrm{a}}$ & 17 & 300 & 30 & $249^{\mathrm{a}}$ & 23 \\
\hline 3 & 8 & 218 & 18 & 237 & 26 & $315^{\mathrm{a}}$ & 52 & 340 & 24 & $277^{a}$ & 33 \\
\hline $\mathrm{C}$ & 4 & 240 & 30 & 239 & 16 & $255^{\mathrm{b}}$ & 16 & 250 & 32 & $254^{\circ}$ & 5 \\
\hline
\end{tabular}

$\mathrm{Hb}$, haemoglobin.

a.b.c,dt Means of groups with different superscript letters were significantly different compared with the previous period $(P<0.05)$.

* For details of Se intake levels, see Table 1.

$\dagger$ For details see p. 70 .

Platelet GSH-Px activity was similar in the treatment groups at the end of the period of low Se intake, but it was somewhat higher in the control group (Table 2 and Fig. 3). Unfortunately, values for the platelet GSH-Px activity in the group with the lowest supplementation level (group 1) are lacking. Se supplementation caused a rapid increase in platelet GSH-Px activity in groups 2 and 3, the increase between week 6 and week 9 being significantly different from the control group $(P=0.041)$. Platelet GSH-Px activity appeared to have stabilized at the end of the supplementation period, and was somewhat higher in the group with the highest Se intake (group 3). Although the decrease between weeks 14 and 24 was significantly larger in groups 2 and 3 than in group $C$, at the end of the post-intervention period the enzyme activity in groups 2 and 3 was still elevated as compared to baseline values.

Se balance. Mean urinary and faecal Se excretion of the twenty-three subjects was 18 (SE 4) and 21 (SE 5) $\mu \mathrm{g} / \mathrm{d}$ during the pre-intervention period, when they were still on their 


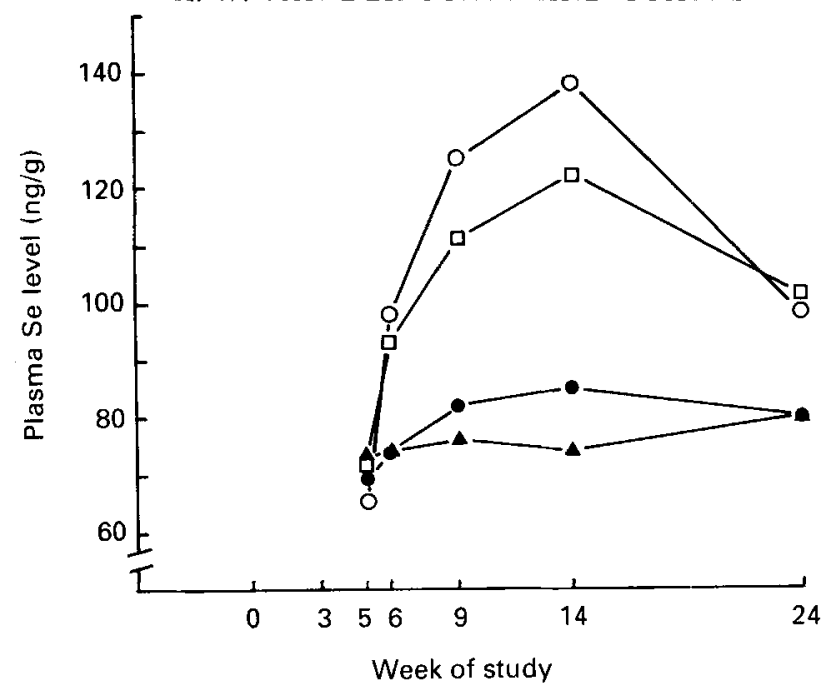

Fig, 1. Plasma selenium concentrations in groups $1(\mathbf{O}), 2(\square), 3(O)$ and controls $(\mathbf{C})(\mathbf{A})$, during the period of Se supplementation (weeks 5-14) when they received 55, 135, 215 and $0 \mu \mathrm{g} \mathrm{Se} / \mathrm{d}$ as Se-rich bread or meat respectively, and during the post-intervention period (weeks 14-24). Each point represents the mean of four to eight subjects. For experimental details, see pp. $70-72$.

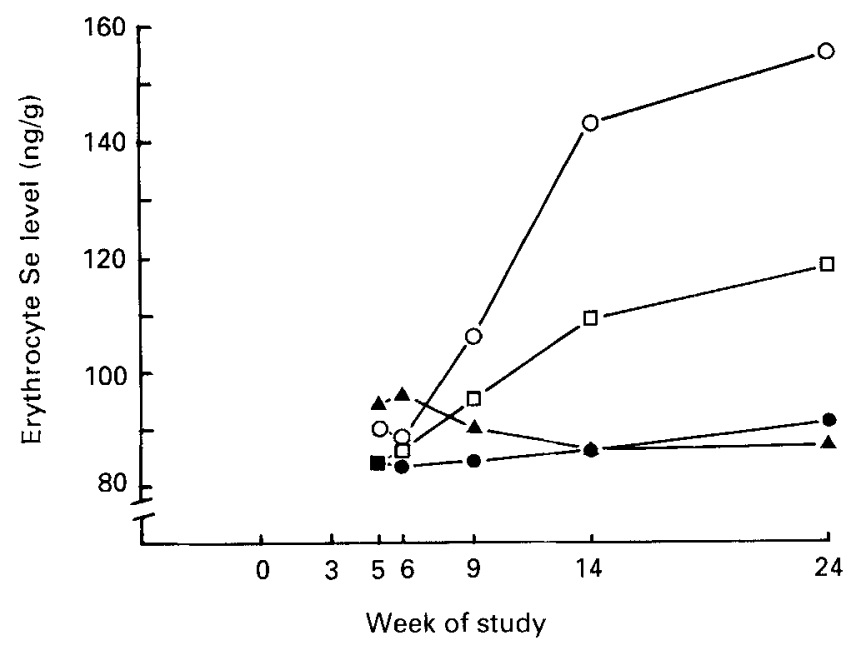

Fig. 2. Erythrocyte selenium concentrations in groups $1(\mathbf{O}), 2(\square), 3(O)$ and controls $(C)(\boldsymbol{A})$ during the period of Se supplementation (weeks 5-14) when they received $55,135,215$ and $0 \mu \mathrm{g} \mathrm{Se} / \mathrm{d}$ as Se-rich bread or meat respectively, and during the post-intervention period (weeks 14-24). Each point represents the mean of four to eight subjects. For experimental details, see pp. $70-72$.

habitual diets. The balance values collected over the last $12 \mathrm{~d}$ of both the low-Se period and supplementation period are summarized in Table 3. During the low-Se period, Se concentrations in the urine and faeces were similar for all groups. Due to the difference in Se intake level there was a net loss of $11 \mu \mathrm{g} / \mathrm{d}$ in group 1 , whereas the balance of the subjects in groups 2 and 3 was slightly positive, with a retention of about $10 \mu \mathrm{g} / \mathrm{d}$.

Se supplementation resulted in a considerable increase in urinary Se excretion in groups 2 and 3 , whereas there was only a slight increase in faecal Se excretion. The total loss of 


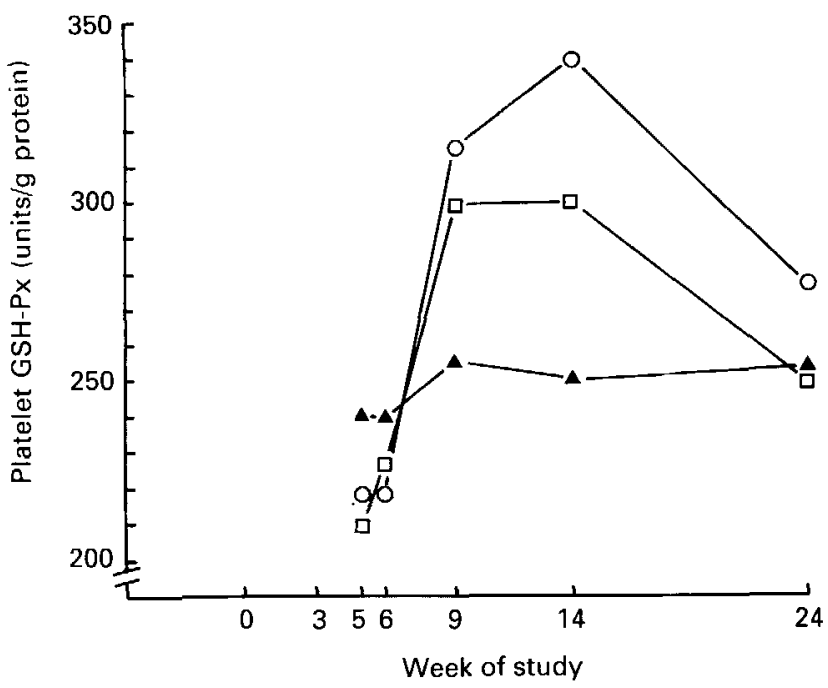

Fig. 3. Platelet glutathione peroxidase (EC 1.11.1.9; GSH-Px) activity in groups $2(\square), 3(\mathrm{O})$ and controls (C) (A) during the period of selenium supplementation (weeks $5-14$ ) when they received 135,215 and $0 \mu \mathrm{g} \mathrm{Se} / \mathrm{d}$ as Se-rich bread or meat respectively and during the post-intervention period (weeks 14-24). Each point represents the mean of four to eight subjects. For experimental details, see pp. 70-72.

Table 3. Selenium balance ( $\mu \mathrm{g} / d$ ) during the low-Se period (weeks 4-5) and during the period of Se supplementation (weeks 13-14)*

\begin{tabular}{|c|c|c|c|c|c|c|c|c|c|c|c|c|c|c|c|}
\hline \multirow[b]{3}{*}{$\begin{array}{l}\text { Dietary } \\
\text { group } t\end{array}$} & \multirow[b]{3}{*}{$n$} & \multicolumn{7}{|c|}{ Weeks 4-5 } & \multicolumn{7}{|c|}{ Weeks $13-14$} \\
\hline & & \multicolumn{2}{|c|}{ Urine } & \multicolumn{2}{|c|}{ Facces } & \multicolumn{2}{|c|}{ Balance } & \multirow{2}{*}{$\begin{array}{c}\text { Mean } \\
\text { apparent } \\
\text { absorption }\end{array}$} & \multicolumn{2}{|c|}{ Urine } & \multicolumn{2}{|c|}{ Faeces } & \multicolumn{2}{|c|}{ Balance } & \multirow{2}{*}{$\begin{array}{c}\text { Mean } \\
\text { apparent } \\
\text { absorption }\end{array}$} \\
\hline & & Mean & SD & Mean & SD & Mean & $\mathrm{SD}$ & & Mean & so & Mean & SD & Mean & SD & \\
\hline $1 b$ & 4 & 16 & 2 & 20 & 4 & -9 & 5 & 26 & $24^{a}$ & 4 & $29^{2}$ & 4 & $15^{a}$ & 5 & 57 \\
\hline $1 \mathrm{~m}$ & 4 & 18 & 2 & 24 & 3 & -14 & 5 & 11 & $18^{a}$ & 2 & $26^{\mathrm{n}}$ & 4 & $-2^{\mathrm{a}}$ & 5 & 38 \\
\hline $2 b$ & 4 & 17 & 2 & 20 & 2 & 7 & 1 & 53 & $47^{b}$ & 2 & $38^{c}$ & 8 & $52^{\mathrm{b}}$ & 4 & 73 \\
\hline $2 \mathrm{~m}$ & 3 & 15 & 2 & 19 & 1 & 8 & 2 & 56 & $40^{b}$ & 10 & $33^{* x}$ & 5 & $60^{\mathrm{bnd}}$ & 11 & 75 \\
\hline $3 b$ & 4 & 15 & 3 & 18 & 3 & 11 & 3 & 58 & $83^{\mathrm{e}}$ & 13 & $59^{d}$ & 5 & $85^{\mathrm{C}}$ & 16 & 74 \\
\hline $3 \mathrm{~m}$ & 4 & 15 & 3 & 17 & 5 & 11 & 3 & 60 & $92^{\mathrm{c}}$ & 13 & $42^{e}$ & 4 & $71^{\mathrm{d}}$ & 10 & 80 \\
\hline
\end{tabular}

b, Bread; $m$, meat.

a.b,c,d Means of groups with different superscript letters were significantly different compared with the previous period $(P<0 \cdot 05)$.

* For details on Se intake levels, see Table 1.

$\dagger$ For details, see p. 70.

t. Apparent absorption $(\%)=($ Se intake - faccal Sc $/$ Se intake $) \times 100$.

Se by excretion in the urine averaged $46 \%$ for all groups during the period of low Se intake and $43 \%$ for group 1, 55\% for group 2 and $64 \%$ for group 3 after Se supplementation. For all subjects except those in group 1 receiving the meat supplements, the difference between total Se intake and the combined urinary and faecal excretion was positive.

Except for the difference in Se balance in group 3, where the bread group had a 


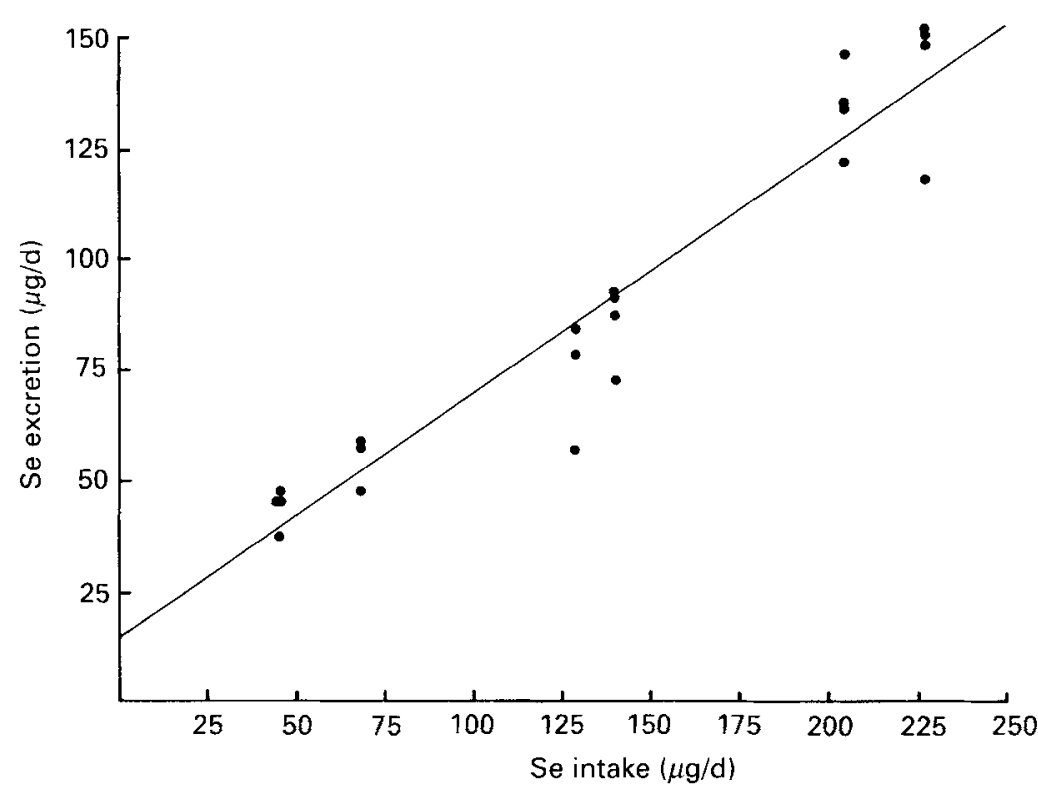

Fig. 4. Regression of selenium excretion $v$. Se intake at the end of the supplementation period for the groups $1 \mathrm{~b}$, $1 \mathrm{~m}, 2 \mathrm{~b}, 2 \mathrm{~m}, 3 \mathrm{~b}$ and $3 \mathrm{~m}$ when they received $68,42,140,129,227$ and $205 \mu \mathrm{g} \mathrm{Se} / \mathrm{d}$ as Se-rich bread or meat respectively. For experimental details, see pp. 70-72. $y=14 \cdot 8+0 \cdot 55 x(r 0 \cdot 96, n 22)$.

significantly higher retention $(P=0.031)$, there were no significant differences between the meat and bread supplements. The difference between bread and meat disappeared after adjustment for the difference in Se-content between these products.

Linear regression analyses of Se excretion in urine and faeces $v$. Se intake during the supplementation period yielded the equation $y=14.8+0 \cdot 55 x$, from which the level of intake $(x)$ at which intake equals excretion $(y)$, was calculated as $32.9 \mu \mathrm{g} \mathrm{Se} / \mathrm{d}$ (Fig. 4).

\section{DISCUSSION}

The small decreases in plasma and erythrocyte Se levels during the low-Se period suggest that the habitual Se intake level differed only slightly from the level in that period. The mean plasma and erythrocyte Se levels of 68 and $86 \mathrm{ng} / \mathrm{mg}$ respectively at the start of the supplementation period were similar to those found in Finnish men on a Se intake level of $56 \mu \mathrm{g} / \mathrm{d}$ (Levander et al. 1983).

The rapid increase in plasma $\mathrm{Se}$ is in fair agreement with other studies, showing that plasma Se is a sensitive index of recent Se intake (Levander et al. 1983; Luo et al. 1985a; Thomson et al. 1985). Moreover, the increase in plasma Se was significantly dependent on Se intake level. It was most pronounced during the first 5 weeks of supplementation whereafter it levelled off at $85(95 \%$ CI 78.5-91.5), $122(110 \cdot 7-133 \cdot 3)$ and $138(127 \cdot 4-148 \cdot 6)$ for groups 1, 2 and 3 respectively receiving 55,135 and $215 \mu \mathrm{g} \mathrm{Se} / \mathrm{d}$.

The lag time preceding the increase in erythrocyte Se level may be partly explained by the time-period required for the development of the erythroid cells in the bone marrow which has been estimated to be 10-14 d (Cohen et al. 1988). Johansson et al. (1983) suggest that the bone marrow is important for the distribution of Se among different types of blood cells. The continued increase in erythrocyte Se level after supplementation had been discontinued could reflect Se retention in the bone marrow. Further, erythrocytes have a 
half-life of $120 \mathrm{~d}$, so erythrocyte Se levels refleci Se intake in the long term. At the end of the supplementation period, the erythrocyte Se reached values of 86 (78.7-93.3), 109 (93.4-124.7) and $143(125 \cdot 1-160 \cdot 9)$ for groups 1,2 and 3 respectively.

The GSH-Px activity in plasma and erythrocytes apparently had already reached a plateau before the start of the intervention period, indicating that in the present study these indices were not very useful for the assessment of Se bioavailability.

In contrast, the GSH-Px activity in platelets increased rapidly and significantly and tended to plateau after 5 weeks of supplementation at levels of 299 (95\% CI 284.2-313.8), $315(272.7-357.3)$ respectively for groups 2 and 3 . This finding is in agreement with the results found in Finnish men: supplementation with Se-rich wheat or selenite resulted in a significant rapid increase in platelet GSH-Px, whereafter a plateau was reached (Levander et al. 1983).

Recently, Thomson et al. (1988) have demonstrated the suitability of the platelet GSHPx assay for the assessment of Se bioavailability in men. They confirm the conclusions from rat studies that platelet GSH-Px reflects Se in the liver, which is in rats affected most by changes in Se intake (Levander, 1983).

Our results do not indicate a difference in bioavailability of Se between meat and bread supplements as measured by platelet GSH-Px. Both sources caused similar values for platelet enzyme activity, even in the post-intervention period. Unfortunately, there was no information available on the response of platelet GSH-Px activity to supplementation with $55 \mu \mathrm{g} \mathrm{Se} / \mathrm{d}$. The other two doses may have been too high to distinguish between the bioavailability of the two Se sources. The only difference between the two sources lies in the higher erythrocyte Se concentration in the meat groups at the end of the post-intervention period. This can hardly be explained by the difference in Se intake through the two Se sources because the intake was on average $10 \%$ higher through the bread supplements than through the meat supplements.

Although subject to much criticism (Isaksson \& Sjögren, 1967; Hegsted, 1975), balance studies have been widely used to estimate nutrient requirements. We feel that balance studies can provide useful information, provided results are interpreted with caution. As indicated by Mertz (1987) a balance study does not determine the requirement in general, but the supply needed to maintain the existing pool size. Mertz (1987) supposes that only if the adequacy of the status of a nutrient has been proved by independent methods, can the results be used as a basis for dietary recommendations.

When our subjects were on a self-selected diet, their mean daily faecal and urinary Se losses were $39 \mu \mathrm{g}$. These values are only half the amounts reported for American adult men on self-selected diets who needed $82 \mu \mathrm{g} \mathrm{Se} / \mathrm{d}$ to compensate for faecal and urinary losses (Levander \& Morris, 1984). Findings from an extremely low-Se area in China indicate a mean urinary and faecal output of $7.1 \mu \mathrm{g} \mathrm{Se} / \mathrm{d}$ (Luo et al. 1985b). The differences remain considerable, even after correction for body-weight.

The results of the Se balance study at the end of the low-Se period support the suggestion that the habitual Se intake of our subjects was approximately $30-40 \mu \mathrm{g} / \mathrm{d}$. Moreover, linear regression analysis of excretion on a wide range of Se intake levels during the supplementation period indicated that our subjects needed about $33 \mu \mathrm{g} \mathrm{Se} / \mathrm{d}$ to compensate for urinary and faecal losses.

As the Se intake increased, the major route of Se excretion shifted from faeces to urine, indicating the important role of the kidneys in homeostatic regulation. However, in spite of the increased Se excretion at the end of the supplementation period the intake exceeded the Se output resulting in Se retention. Since the Se intake levels during the supplementation period were close to the recommended range of $50-200 \mu \mathrm{g} / \mathrm{d}$ (Food and Nutrition Board, 1980), the attainment of a new equilibrium was expected to be only a matter of time. Tracer 
studies have indicated that Se, particularly in the form of selenomethionine, can be incorporated efficiently into body tissues. The biological half-life of Se in various tissues appears to be largely dependent on metabolic factors of individual tissues. The whole body turnover period of ${ }^{75} \mathrm{Se}$ has been estimated at 245 and $116 \mathrm{~d}$ after an oral dose of $\left[{ }^{75}\right.$ Se]selenomethionine and $\left[{ }^{75}\right.$ Se]selenite respectively (Thomson \& Stewart, 1974; Griffiths et al. 1976). Assuming that in our study the predominant form of Se was selenomethionine, the relative low turnover rate of this form may partly explain the Se retention shown.

We did not take into account losses via expired air, sweat or skin. Other studies suggest that these are negligible (Griffiths et al. 1976; Levander et al. 1981; Molin \& Wester, 1976; Thomson \& Stewart, 1974). Besides, only moderate sport activities were allowed during the trial to reduce Se losses via perspiration.

It is uncertain whether the significant difference in Se balance between the meat and bread supplements in group 3 is of any importance. This difference was most probably the result of a $10 \%$ higher Se intake via the bread supplements.

The high apparent absorption $(76 \%)$ found in our study in the two highest supplementation groups (groups 2 and 3 ) is in agreement with the apparent absorption of $76 \%$ found in a New Zealand study after supplementation with selenomethionine (Robinson et al. 1978). There was no difference in apparent absorption between the meat and bread supplements. The very low values found in our study $(11,26$ and $38 \%$ in the subgroups of group 1) point to the relatively high endogenous Se losses when the subjects were in negative balance.

The results of the present study indicate that the bioavailability of Se was similar from bread and meat. Both supplements were absorbed in equal proportions and had the same effect on Se concentrations in plasma and erythrocytes. Even the conversion to a biologically active form, as measured by platelet GSH-Px activity, was similar.

It has been suggested that the dietary Se level causing the GSH-Px activity to plateau can be considered as an estimate of Se requirement (Levander et al. 1983; Nève ef al. 1988). If we examine the GSH-Px activity in different blood compartments, we notice that enzyme activity in plasma and erythrocytes is saturated at the habitual intake level, whereas platelet GSH-Px responds to Se supplementation.

The question remaining to be answered now is at which intake of Se the physiological requirement will be met, and when we may consider supra-adequate levels of Se intake to have possible beneficial effect. The exact nature and function of the GSH-Px and possibly other Se compounds remains to be elucidated before an optimal dietary Se intake level can be established.

The study was supported by the NWO-Foundation for Medical and Health Research MEDIGON. The authors thank the subjects for their cooperation. They are grateful to Stanny Pelupessy, Liesbeth Schulp, Hillie van Steenbrugge and Anneke Wesstra for their technical assistance and Evelien Aarnink for data processing. They greatly appreciate the assistance of Professor Ivan S. Palmer of South Dakota State University in purchasing the Se-rich wheat and meat.

\section{REFERENCES}

Cochran, W. G. \& Cox, G. M. (1957). Experimental Designs, New York: John Wiley \& Sons.

Cohen, H. J., Brown, M., Lyons, J., Avissar, N., Hamilton, D. \& Liegey, P. (1988). Clinical physiological and biochemical consequences of human selenium deficiency. In Essential and Toxic Trace Elements in Human Health and Disease, pp. 201-210 [A. S. Prasad, editor]. New York: Alan R. Liss.

Food and Nutrition Board (1980). Recommended Dietary Allowances, 9th revised ed. Washington, DC: National Academy of Sciences. 
Griffiths, N. M., Stewart, R. D. H. \& Robinson, M. F. (1976). The metabolism of $\left[{ }^{75}\right.$ Se]selenomethionine in four women. British Journal of Nutrition 35, 373-382.

Hegsted, D. M. (1975). Balance studies. Journal of Nutrition 106, $307 \cdot 311$.

Ip, C. (1985). Selenium inhibition of chemical carcinogenesis. Federation Proceedings 44, 2573-2578.

Ip, C. (1988). Differential effect of dietary methionine on the biopotency of selenomethionine and selenite in cancer chemoprevention. Journal of the National Cancer Institute 80, 258-262.

Isaksson, B. \& Sjögren, B. (1967). A critical evaluation of the mineral and nitrogen balances in man. Proceedings of the Nutrition Society 26, $106-116$.

Johansson, E., Lindh, U. \& Landstrom, E. (1983). The incorporation of selenium and alterations of macro- and trace element levels in individual blood cells following supplementation with sodium selenite and vitamin $\mathrm{E}$. A nuclear microprobe application. Biological Trace Element Research 5, 433 447.

Keshan Disease Research Group (1979a). Observations on effect of sodium selenite in prevention of Keshan disease. Chinese Medical Journal 92, 471-476.

Keshan Disease Research Group. (1979b). Epidemiologic studies on the ethiologic relationship of selenium and Keshan disease. Chinese Medical Journal 92, 777-782.

Koh, T. S. \& Benson, T, H. (1983). Metals and other elements. Critical re-appraisal of fluorimetric method for determination of selenium in biological materials. Journal of the Association of Official Analytical Chemists $\mathbf{6 6}$, $918-926$.

Levander, O. A. (1983). Considerations in the design of selenium bioavailability studies. Federation Proceedings 42, $1721-1725$.

Levander, O. A., Alfthan, G., Arvilommi, H., Gref, C. G., Huttunnen, J. K., Kataja, M., Koivistoinen, P. \& Pikkarainen, J. (1983). Bioavailability of selenium to Finnish men as assessed by platelet glutathione peroxidase activity and other blood parameters. American Journal of Clinical Nutrition 37, 887-897.

Levander, O. A. \& Morris, V. C. (1984). Dietary selenium levels needed to maintain balance in North American adults consuming self-selected diets. American Journal of Clinical Nutrition 39, 809-815.

Levander, O. A., Sutherland, B., Morris, V. C. \& King, J. C. (1981). Selenium metabolism in human nutrition. In Selenium in Biology and Medicine, pp. 256-268 [J. E. Spallholz, J. L. Martin and H. E. Ganther, editors]. Westport, CT: AVI Publishing Co.

Lowry, O. H., Rosebrough, N. J., Farr, A. L. \& Randall, R. J. (1951). Protein measurement with the Folin phenol reagent. Journal of Biological Chemistry 193, 265-275.

Luo, X., Wei, H., Yang, C., Xing, J., Liu, X., Qiao, C., Feng, Y., Liu, J., Liu, Y., Wu, Q., Liu, X., Guo, J., Stoecker, B. J., Spallholz, J. E. \& Yang, S. P. (1985a). Bioavailability of selenium to residents in a low selenium area of China. American Joumal of Clinical Nutrition 42, 439-448.

Luo, X., Wei, H., Yang, C., Xing, J., Qiao, C, Feng, Y., Liu, J., Liu, Z., Wu, Q., Liu, Y., Stoecker, B. J., Spallholz, J. E. \& Yang, S. P. (1985b). Selenium intake and metabolic balance of 10 men from a low selenium area of China. American Journal of Clinical Nutrition 42, 31-37.

Mert7, W. (1987). Use and misuse of balance studies. Journal of Nutrition 117, 1811-1813.

Molin, L. \& Wester, P. O. (1976). The estimated daily loss of trace elements from normal skin by desquamation. Scandinavian Journal of Clinical and Laboratory Investigation 36, 679-682.

Mutanen, M. (1986). Bioavailability of selenium in mushrooms, Boletus edulis, to young women, International Journal for Vitamin and Nutrition Research 56, 297-301.

Nève, J., Vertongen, F, \& Capel, P. (1988). Selenium supplementation in healthy Belgian adults: response in platelet glutathione peroxidase activity and other blood indices. American Journal of Clinical Nutrition $\mathbf{4 8}$, $139-143$.

Pleban, P. A., Munyani, A. \& Beachum, J. (1982). Determination of selenium concentration and glutathione peroxidase activity in plasma and erythrocytes. Clinical Chemistry 28, 311-316.

Robinson, M. F., Rea, H. M., Friend, G. M., Stewart, R. D. H., Snow, P. C. \& Thomson, C. D. (1978), On supplementing the selenium intake of New Zealanders. 2. Prolonged metabolic experiments with daily supplements of selenomethionine, selenite and fish. British Journal of Nutrition 39, $589 \cdot 600$.

Snedecor, G. W. \& Cochran, W. G. (1967). Statistical Methods. Ames, Iowa: Iowa State University Press.

Tangney, C. C., McNair, H. N. \& Driskell, J. A. (1981). Quantitation of individual tocopherols in plasma, platelets, lipids and livers by high-performance liquid chromatography. Journal of Chromatography 224, 389-397.

Thomson, C. D., Ong, L. K. \& Robinson, M. F. (1985). Effects of supplementation with high-selenium bread on selenium, glutathione peroxidase and related enzymes in blood components of New Zealand residents. American Journal of Clinical Nutrition 41, 1015-1022.

Thomson, C. D., Robinson, M. F., Campbell, D. R. \& Rea, H. M. (1982). Effect of prolonged supplementation with daily supplements of selenomethionine and sodium selenite on glutathione peroxidase activity in blood of New Zcaland residents. American Journal of Clinical Nutrition 36, 24-31.

Thomson, C. D., Steven, S. M., Van Rij, A. M., Wade, C. R. \& Robinson, M. F. (1988). Selenium and vitamin E supplementation : activities of glutathione peroxidase in human tissues. American Journal of Clinical Nutrition 48, 316323.

Thomson, C. D. \& Stewart, R. D. H. (1974). The metabolism of $\left[{ }^{75}\right.$ Se]selenite in young women. British Journal of Nutrition 32, 47-57. 
Van Dokkum, W., De Vos, R. H., Muys, Th. \& Wesstra, J. A. (1989). Minerals and trace elements in total diets in The Netherlands. British Journal of Nutrition 61, 7-15.

Van Rij, A. M., Thomson, C. D., McKenzie, J. M. \& Robinson, M. F. (1979). Selenium deficiency in total parenteral nutrition. American Journal of Clinical Nutrition 32, 2076-2085.

Yang, G., Wang, S., Zhou, R. \& Sun, S. (1983). Endemic selenium intoxication of humans in China. American Journal of Clinical Nutrition 37, 872-881. 